\title{
Lithium isotope geochemistry in the Barton Peninsula, King George Island, Antarctica
}

\author{
JONG-SIK RYU ${ }^{1}$, NATHALIE VIGIER ${ }^{2}$, HYE-BIN $\mathrm{CHOI}^{3}$, \\ HYOUN SOO LIM ${ }^{4}$ AND JEONGHOON LEE ${ }^{5}$ \\ ${ }^{1}$ Pukyong National University \\ ${ }^{2}$ LOV - CNRS - Sorbonne Université \\ ${ }^{3}$ Korea Basic Science Institute \\ ${ }^{4}$ Pusan National University \\ ${ }^{5}$ Ewha Womans University \\ Presenting Author: jongsikryu@gmail.com
}

Lithium (Li) has two stable isotopes, ${ }^{6} \mathrm{Li}$ and ${ }^{7} \mathrm{Li}$, whose large relative mass difference is responsible for significant isotopic fractionation during physico-chemical processes. Thus $\mathrm{Li}$ isotopes are a good tracer of continental chemical weathering. Although physical erosion is dominant in the Polar regions due to cold climate and limited river systems, increasing global surface temperature may enhance chemical weathering, with possible consequences on carbon cycle and nutriment flux to the ocean. Fine fractions of soils have been forming during the last $6000 \mathrm{yr}$ since the last deglaciation under warmer and more humid climate than other parts of Antarctica. Here, we examined elemental and Li isotope geochemistry of meltwaters, suspended sediments, soils and bedrocks in the Barton Peninsula, King George Island, Antarctica. Li concentrations range from $8.7 \mathrm{nM}$ to $23.3 \mu \mathrm{M}$ in water, from $0.01 \mathrm{ppm}$ to $1.43 \mathrm{ppm}$ in suspended sediment, from $9.56 \mathrm{ppm}$ to $36.9 \mathrm{ppm}$ in soil, and from $0.42 \mathrm{ppm}$ to $28.3 \mathrm{ppm}$ in bedrock. $\delta^{7} \mathrm{Li}$ values are also variable, ranging from +16.4 to $+41.1 \%$ in water, from -0.4 to $+13.4 \%$ in suspended sediment, from -2.5 to $+6.9 \%$ in soil, and from -1.8 to $+11.7 \%$ in bedrock. Correlation between elemental and $\mathrm{Li}$ isotope geochemistry reveals that both congruent and incongruent dissolution controls $\delta^{7} \mathrm{Li}$ values of water, rather than seasalt inputs from atmosphere or ice melting. Furthermore, PHREEQC modeling indicates that Fe-oxyhydroxides are oversaturatued in some meltwater, explaning their high $\delta^{7} \mathrm{Li}$ values that resulted from preferential uptake of ${ }^{6} \mathrm{Li}$. Likewise, $\delta^{7} \mathrm{Li}$ values of suspended sediment indicate are mostly caused by modern weathering. These results confirm that increasing global surface temperature enhances mordern chemical weathering in Antarctica, which therefore is expected to be stronger with time. 